\title{
RESENHA
}

dof" http://dx.doi.org/10.15448/1980-864X.2016.3.25662

\section{Diferentes faces da direita portuguesa no Estado Novo salazarista}

\author{
Different faces of the Portuguese right in the \\ Estado Novo of Salazar \\ Las diferentes formas de la derecha portuguesa en el \\ Estado Nuevo de Salazar
}

Maria Paula Nascimento Araujo*

RESENHA DE:

PINTO, António Costa. Os Camisas-Azuis: Rolão Preto e o Fascismo em Portugal. Porto. Alegre; Recife: EdiPUCRS; EDUPE, 2016.

PINTO, António Costa. Os Camisas Azuis e Salazar: Rolão Preto e o Fascismo em Portugal. Lisboa: Edições 70, 2015.

O livro do historiador e cientista político português, António Costa Pinto chega ao Brasil num momento em que se reforçam os laços de intercâmbio acadêmico entre os dois países. Laços que, entre outras direções, procuram investigar as experiências de ditadura, de lutas políticas e de redemocratização vividas no mundo lusófono. Neste campo uma das contribuições mais significativas da produção de Costa Pinto tem sido no estudo do pensamento, práticas políticas e formas de organização da direita em Portugal.

\footnotetext{
*Professora Associada do Instituto de História da Universidade Federal do Rio de Janeiro (UFRJ).

<mp-araujo@uol.com.br><dados biográficos/biographic data>
} 
O livro que é resultado da tese de doutoramento, concluída em 1992 no Instituto Universitário Europeu em Florença, foi publicado pela primeira vez em 1994 pela Editorial Estampa com o título Os Camisas Azuis: ideologia, elites e movimentos fascistas em Portugal. Em 2000 recebeu uma edição nos EUA, The Blue Shirts: Portuguese Fascism in Inter-war Europe e no ano seguinte uma versão em italiano Fascismo e Nazionalesindacalismo in Portogallo, 1914-1945. Em 2015, com atualização do autor, nova versão foi preparada em Portugal pela Edições 70. No ano seguinte foi lançada pelas editoras universitárias da Pontifícia Universidade Católica do Rio Grande do Sul e Universidade de Pernambuco, uma publicação para o público brasileiro. ${ }^{1}$

Neste livro Costa Pinto analisa o fascismo português representado pelo movimento Nacional-Sindicalista, fundado em 1932 e tornado ilegal em 1934, por Salazar. Seus militantes identificavam-se por portar camisas azuis e eram reconhecidos por esta indumentária específica, como os "camisas pretas" de Mussolini, os "camisas pardas" dos nazistas alemães e os "camisas verdes" dos integralistas brasileiros. Não era apenas na referência ao vestuário que os fascistas portugueses demonstravam sua identificação com o nazi-fascismo europeu. Rolão Preto, o líder do movimento, ostentava um bigode semelhante ao de Hitler e era chamado de "Chefe" pelos militantes. As manifestações públicas do Nacional-Sindicalismo reproduziam a coreografia fascista: os desfiles paramilitares, a saudação com o braço estendido, as canções de combate. Usavam também a cruz de malta portuguesa da mesma forma que os nazistas usavam a suástica, em bandeiras, cartazes e braçadeiras. Assim como o fascismo italiano e alemão, o NacionalSindicalismo voltava-se com empenho para as classes trabalhadores, confrontando-se violentamente com os comunistas, disputando com eles a simpatia e adesão dos trabalhadores portugueses e propondo formas próprias para a resolução da "questão social". Um caderno de imagens inserido no livro ilustra a estética e a retórica do fascismo português. Num cartaz ilustrado pela imagem de Rolão Preto e pela sigla do Nacional-Sindicalismo aparece a frase: É preciso que os muito ricos sejam menos ricos para que os muito pobres sejam menos pobres. E logo abaixo a afirmação: Temos uma doutrina, uma força e um chefe. Era desta forma que o movimento se apresentava aos trabalhadores.

\footnotetext{
${ }_{1}^{1}$ Nesta resenha optei por citar a edição portuguesa (PINTO, 2015).
} 
Para Costa Pinto, o Nacional-Sindicalismo representou uma das tentativas mais bem-sucedidas da extrema direita de penetrar no movimento operário e sindical, com publicações destinadas especialmente aos trabalhadores, distribuídas gratuitamente nas fábricas. Mas, apesar disso, o movimento se esvaziou dois anos depois de sua fundação, tendo sido declarado ilegal por Salazar e vendo uma parte de seus líderes tomar o caminho do exílio e outra parte ser cooptada pelo Estado Novo.

$\mathrm{O}$ autor analisa a gênese e o colapso deste movimento. Nesta investigação dá especial destaque ao Integralismo Lusitano, movimento de direita, de inspiração monárquica, nascido na Universidade de Coimbra, contra a República implantada em 1910. Costa Pinto mostra a importância da Universidade de Coimbra, como berço do pensamento da direita portuguesa e recupera as redes de sociabilidade formadas por estudantes e professores de Direito. Coimbra, a velha cidade universitária, aparece como um polo de formulações e ações políticas. Foi lá que, nas vésperas da Primeira Guerra Mundial, jovens estudantes monárquicos fundaram uma revista e um clube chamado Integralismo Lusitano. Muitos destes jovens participaram das primeiras revoltas monárquicas contra a República, vários deles viveram alguns anos exilados na França e na Bélgica (absorvendo influências das organizações de direita, em especial a Action Française). No retono a Portugal organizaram-se como um movimento político em 1916, quando o regime republicano declarou apoio aos aliados na guerra. O projeto do Integralismo apontava para a restauração de uma monarquia corporativa, antiliberal, descentralizada e tradicionalista. Rolão Preto, que havia passado pelo exílio, foi o mais jovem fundador do movimento. O Integralismo, segundo Costa Pinto, deixou uma marca intelectual profunda na cultura política portuguesa do século XX. De certa forma, ele pode ser visto como a matriz fundamental de todas as correntes do pensamento de direita em Portugal. E foram justamente estudantes do Integralismo Lusitano que fundaram, em fevereiro de 1932, o jornal A Revolução, embrião do fascismo português. Meses mais tarde o grupo convidou Rolão Preto, membro destacado do Integralismo, a ser o diretor do jornal. No verão daquele ano foi lançado oficialmente o Movimento NacionalSindicalista que veio a ser a expressão do fascismo em Portugal. São, portanto, íntimas as relações entre o Integralismo Lusitano e o fascismo português.

Mas, apesar desta influência e, principalmente de sua origem derivada das fileiras do Integralismo Lusitano, os fascistas portugueses 
distinguiam-se dos Integralistas. A elite política fascista contestava o reacionarismo tradicionalista do Integralismo Lusitano, em especial sua posição monarquista e se apresentava como uma direita radical e dinâmica. O Nacional-Sindicalismo foi, portanto, uma manifestação tardia e minoritária, de uma corrente fascista no interir do vasto campo da direita portuguesa antiliberal e autoritária. Mas a alternativa fascista foi rapidamente esmagada pelos pactos entre Salazar e os grupos conservadores que, junto com as elites militares, compunham a força dominante do Estado Novo.

A característica de "tardio" é também fundamental para a compreensão do fascismo português. Este fascismo tardio não acompanhou o nascimento de seus congêneres alemães e italianos, ao longo da década de 1920. O movimento Nacional-Sindicalista foi fundado em 1932 quando já estavam bastante adiantados os arranjos políticos de Salazar em torno das antigas elites conservadoras. Mais do que isso: em função desta criação tardia foram os Integralistas - e não os fascistas - os principais atores políticos do golpe militar de 1926 que derrubou a República e o liberalismo português. A ausência dos fascistas portugueses nos anos 1920 poderia explicar porque estes não foram os atores prioritários da construção da nova ordem política autoritária que surgiu após a derrubada da República. Um processo bastante diferente do que ocorreu em outros países como Alemanha, Itália e Espanha, onde os fascistas estiveram inteiramente envolvidos com a queda dos regimes liberais e por isso mesmo foram atores primordiais da construção dos novos regimes autoritários que daí decorreram.

A análise de Costa Pinto realça a distinção entre os fascistas e a ditadura salazarista e este é um dos argumentos centrais do livro. Este argumento rendeu uma polêmica importante por ocasião do lançamento da primeira edição portuguesa do livro. Afirmar a distinção entre os fascistas e a ditadura salazarista implicava em retirar desta última o rótulo de ditadura fascista. Se os "camisas azuis" eram os representantes do fascismo português e eram reprimidos pela ditadura salazarista, como caracterizá-la politicamente? O Estado Novo era uma ditadura fascista ou não? O livro de Costa Pinto acendeu a polêmica em torno da classificação do regime autoritário de Salazar. Apostando no rigor conceitual para a análise e classificação dos diferentes tipos de regimes autoritários, Costa Pinto investigou em detalhes as relações e confrontos entre Salazar e o Nacional-Sindicalismo. Relações tensas na qual o Estado Novo tentava subjugar e controlar o movimento, estabelecendo censura aos seus jornais, proibindo manifestações públicas e a existência 
de sedes. As tensas relações terminaram com uma cisão do movimento Nacional-Sindicalista numa ala pró Salazar que foi cooptada para cargos políticos do Estado Novo. O grupo de Rolão Preto teve que escolher entre integração ou exílio. Em julho 1934 o movimento foi declarado ilegal por meio de uma nota oficiosa de Salazar.

A perspectiva de Costa Pinto é salientar e analisar os conteúdos específicos das diferentes expressões da direita portuguesa que interagem nas primeiras décadas do século XX: o Integralismo Lusitano, o Estado Novo e o Nacional-Sindicalismo dos "camisas azuis". Três fenômenos distintos que se inter-relacionam, se influenciam e se contrapõem. $\mathrm{O}$ Integralismo Lusitano, movimento de base monárquica, tradicional e conservador, antiliberal e antiparlamentar, apelando fortemente para o nacionalismo. O Estado Novo salazarista, que consagra um regime de partido único, autoritário, conservador, católico e, à semelhança do Integralismo, antiliberal e antiparlamentarista, apoiado nas elites militares. E o Movimento Nacional-Sindicalista que se espelhava nos movimentos fascistas europeus e procurava reproduzir suas características. E não era apenas o conservadorismo clerical que afastava Salazar dos "camisas azuis. Segundo costa Pinto, "Salazar manteve desde finais de 1932 uma distância prudente face à ação dos nacional-sindicalistas e não perdeu nenhuma oportunidade para deles se demarcar no campo doutrinário e político" (PINTO, 2015, p. 250). Em especial Salazar procurou expressar, em várias entrevistas, seu desacordo em relação à ação milicial e a chefia carismática dos ditadores fascistas.

Para Costa Pinto a iniciativa de Salazar que teve maior impacto sobre o movimento Nacional-Sindicalismo foi a promulgação da legislação corporativa no verão de 1933. O corporativismo era um dos temas centrais do programa dos "camisas azuis", mas o Estatuto do Trabalho Nacional, promulgado pelo Estado Novo não os aproximou. Pelo contrário, criou uma distância maior entre Salazar e os fascistas. Não tanto pelas diferenças entre as propostas de corporativismo que porventura houvesse entre o governo e os fascistas, mas essencialmente, porque os "camisas azuis" foram alijados do processo. Nenhum integrante do Nacional-Sindicalismo foi chamado a colaborar no Estatuto nem integrou a construção do edifício corporativo. O Estado Novo, na verdade, roubou-lhes a bandeira.

Após o verão de 1933 Salazar aumentou a perseguição ao NacionalSindicalismo. Em julho de 1934 o movimento foi declarado ilegal e Rolão Preto rumou para o exílio. Foi curta, portanto, a vida política dos 
fascistas portugueses, mas eles representaram um embate importante no cenário político conservador de Portugal na década de 1930. Um cenário dominado pelo vasto campo de direita no qual se confrontavam distintos elementos: do dinamismo autoritário dos fascistas ao conservadorismo tradicionalista de matriz monárquico, passando pelo conservadorismo clerical e pelas elites militares, o Estado Novo foi palco de disputas entre diferentes grupos de direita. Salazar conseguiu amalgamar e dirigir o conjunto destes grupos. O governo foi capaz inclusive de absorver, em sua estrutura, antigos membros do Nacional-Sindicalismo após o movimento ter sido declarado ilegal.

O livro procura, portanto, distinguir integralismo, fascismo e salazarismo, procurando entender a força motriz de cada um destes fenômenos. O Estado Novo foi sempre um "símbolo da hegemonia ideológica de uma direita antidemocrática de matriz tradicionalista e católica" (PINTO, 2015, p. 338). Já a elite fascista tinha uma origem política de direita radical, oriunda do Integralismo Lusitano, mas crítica em relação ao seu tradicionalismo.

O substantivo fascismo não se presta, neste livro, a abarcar o conjunto e a diversidade das forças da direita. Cada uma destas manifestações é exaustivamente analisada, sua gênese estudada, seus elementos teóricos e ideológicos definidos, sua base de apoio dissecada, as histórias de vida de seus dirigentes recuperadas. O livro representa ao mesmo tempo, um alentado estudo histórico das direitas portuguesas e uma profunda reflexão conceitual e classificatória onde cada um dos movimentos estudados é visto em sua especificidade. O termo fascismos não é utilizado numa acepção genérica, mas localizada e histórica, designando um movimento específico que, junto com outros, participou da experiência autoritária e conservadora de Portugal na primeira metade do século XX. Compreender a especificidade destas diferentes formas de expressão da direita antidemocrática e autoritária é o objetivo maior deste livro. Plenamente alcançado.

\section{Referências}

PINTO, António Costa. Fascismo e Nazionalesindacalismo in Portogallo, 1914-1945. Roma: Antonio Pellicani Editore, 2001.

. Os Camisas Azuis e Salazar: Rolão Preto e o fascismo em Portugal. Lisboa: Edições 70, 2015.

. Os Camisas Azuis: ideologia, elites e movimentos fascistas em Portugal - 19141945. Lisboa: Editorial Estampa, 1994. 
. Os Camisas Azuis: Rolão Preto e o fascismo em Portugal. Porto Alegre; Recife: EdiPUCRS; EDUPE, 2016.

. The Blue Shirts: Portuguese Fascism in Inter-war Europe. New York: SSMColumbia University Press, 2000.

Recebido: 25 de setembro de 2016 Aprovado: 21 de outubro de 2016

\section{Autora/Author:}

Maria PaUla NASCIMENTo ARAujo <mp-araujo@uol.com.br>

- Professora Associada do Instituto de História da Universidade Federal do Rio de Janeiro (UFRJ), onde integra o Programa de Pós-Graduação em História Social. Doutora em Ciência Política pelo IUPERJ (Instituto Universitário de Pesquisas do Rio de Janeiro). Desenvolve pesquisas sobre a história do tempo presente, com ênfase nos estudos sobre ditaduras e processos de democratização no mundo contemporâneo. É autora, entre outros, de A Utopia Fragmentada: novas esquerdas no Brasil e no mundo na década de 1970" (FGV, 2000); "Memórias Estudantis: da fundação da UNE aos nossos dias" (Relume Dumará, 2007); "História e Memória de Vigário Geral". Coordenou, no Rio de Janeiro, o projeto "Marcas da Memória: história oral da anistia no Brasil", em convênio com a Comissão de Anistia do Ministério da Justiça e outras universidades federais.

- Associate Professor of the History Institute, at the Universidade Federal do Rio de Janeiro (UFRJ). PhD in Political Science from IUPERJ (Instituto Universitário de Pesquisas do Rio de Janeiro). She develops research on the History of Present Time, with emphasis on studies of dictatorships and democratization processes in contemporary world. Author, among others, of "A Utopia Fragmentada: novas esquerdas no Brasil e no mundo na década de 1970" (FGV,2000), and "Memórias Estudantis: da fundação da UNE aos nossos dias" (Relume Dumará, 2007); Coordinated, in Rio de Janeiro, the project "Marks of Memory: Oral History of amnesty in Brazil", in partnership with Amnesty Commission of the Ministry of Justice and other federal universities. 